Bangladesh Journal of Neuroscience 2011; Vol. 27 (2) : 87-93

\title{
Relationship between Histopathological Subtypes of Intracranial Astrocytoma Patients
}

\author{
FAZLE MAHMUD ${ }^{1}$, HARADHAN DEB NATH $^{2}$, KANAK KANTI BARUA $^{3}$, AFZAL HOSSAIN $^{3}$
}

\begin{abstract}
:
Background : The study was carried out in the department of neurosurgery, BSMMU, Dhaka during the period of July 2003 to June 2005. Objective: This study was done to elucidate the relationship between age groups and histopathologicas subtypes in case of intracranial astrocytoma patients. For this purpose, a total number of 44 cases were studied. Results: The mean age of all the patients was 33.1 years (range:1-65 years). The highest incidence was found in the age group of 20 years or below group. Male were more commonly effected than female. WHO grade I astrocytoma was the commonest type. Mean age of low grade astrocytoma (WHO grade II) and glioblastoma were nearly similar to other studies, but the mean age of presentation of grade I astrocytomas patients was little late and for anaplastic actrocytoma a little early in comparison to other study. Conclusion: This showed subtype of astrocytoma has definitive relation to age.
\end{abstract}

Key words: Histopathological subtype, astrocytoma, glioblastoma, oligodendroglyma, ependymoima.

Introduction:

Glial cells are five to ten times more frequent than the trillion brain neurons and compose half the central nervous system (CNS) by volume ${ }^{1}$.

Corresponding to the three histologic groups of glial cells are the following three major types of gliomas: i) astrocytoma, ii) oligodendroglima iii) ependymoma ${ }^{2}$.

Astrocytomas do not fall within discrete, easily definable categories but instead represent a biologic continuum that ranges from hitologically welldifferentiated tumor to poorly or undifferentiated neoplasms with nuclear and cellular pleomorphism, vascular endothelial proliferation and necrosis ${ }^{3}$.

The first widely influential system was devised in 1926 by Bailey and Cushing, who divided these neoplasm into three entities according to their histological similarity to normal embryonic glia 4 .

In 1949, Kernohan et al, proposed a four tiered system based on the degree of anaplasia ${ }^{5}$.
For many years the Kernohan system was the mainstay of pathologic classification of glial tumor and it remains influential today because of its widespread use in the training of pathologists and neuro-pathologists ${ }^{6,7}$.

In 1950, Ringertz proposed a three tiered system that was later popularized by Burger et al and used in many cooperative brain tumor clinical trials ${ }^{8}$.

The most recently introduced grading system is that of the revised World Health Organization?.

Pilocytic astrocytomas presumably arise from a class of astrocytes that is inconspicuous in normal brain but may become prominent in reactive gliosis and neoplasia ${ }^{10}$.

Incidence all gliomas 5\% to $10 \%$ of but account for nearly one third of pediatric neoplasm ${ }^{11}$.

Pilocytic astrocytomas typically are tumors of children and young adults, most tumors in the cerebellum become symptomatic during the first two decades of life ${ }^{12}$.

1. Registrar, Appolo Hospital, Dhaka

2. Assistant Professor, Department of Neurosurgery, Bangabandhu Sheikh Mujib Medical University, Dhaka.

3. Professor, Department of Neurosurgery, Bangabandhu Sheikh Mujib Medical University, Dhaka. 
Pilocytic astrocytomas are characteristically located around the third and fourth ventricles. Less common locations include the brainstem and basal ganglia $^{13}$. The frontal lobe are the most common location of hemispheric pilocytic astrocytoma ${ }^{14}$.

Zulch $^{11}$ showed that average age of intracranial astrocytoma was 36.15 years when it was 31.51 years in Dastur's ${ }^{15}$ series. According to the study of Mc Kernan and Thoma ${ }^{16}$ mean age for low grade astrocytoma was 37.4 years.

Cerebral hemispheres specially frontal (40\%), temporal (25\%), and parietal (25\%) lobes ${ }^{16}$. Others (10\%) include thalamus, midbrain and pons.

Anaplastic Astrocytomas are in Kernohan's grade three and in WHO grade III.

Age incidence of glioblastoma multiforme is usually in patients over 50 years and are rare in patients under 30. Glioblastoma can occasionally be found at any age. ${ }^{2}$ According to Burger P. C. ${ }^{17}$ median age 50 to 60 years.

Incidence of gliomas are $45 \%$ to $50 \% .{ }^{18}$ Any region of CNS possible; cerebral hemispheres predominate (40\% frontal, $25 \%$ temporal, $25 \%$ parietal) ${ }^{19}$.

Symptoms of raised intracranial pressure more common than with lower grade tumors. ${ }^{20}$ Mental status changes and motor deficit also common. Seizure at presentation is approximately $32 \%{ }^{21}$.

\section{Methodology:}

This is a cross sectional study which was carried out at the Department of Neurosurgery, Bangabandhu Sheikh Mujib Medical University (BSMMU). The study was carried out from July 2003 to June 2005. 44 cases were studied. Inclusion criteria are patients with intracranial astrocytomas admitted in dept. of neurosurgery, BSMMU. Exclusion Criteria are patients of intracranial astrocytomas who denied to be included in the study.

A questionnaire was prepared considering the variables such as age and sex of the patient, clinical features, site of tumor, image findings, per operative findings and histopathological reports. Histopathological report of the tumor was collected and then recorded.
Data were processed through computer software SPSS version 11. Statistical calculations were performed by SPSS software. Chi-square test was applied to test for significance and conclusion was drawn at $1 \%$ level of significance.

\section{Results:}

The study was done on 44 patients of intracranial astrocytomas, all patients underwent craniotomy or burr hole biopsy to prove the histopathological diagnosis.

Table-I

Distribution of the cases according to age $(\mathrm{N}=44)$ :

\begin{tabular}{lcc}
\hline $\begin{array}{l}\text { Frequency of } \\
\text { age (years) }\end{array}$ & No. of cases & Percentage \\
\hline$\leq 20$ & 12 & 27.3 \\
$21-30$ & 9 & 20.4 \\
$31-40$ & 11 & 25 \\
$41-50$ & 7 & 15.9 \\
$>50$ & 5 & 11.4 \\
Sex & & \\
Male & 36 & 81 \\
Female & 8 & 19 \\
\hline
\end{tabular}

Table I shows the distribution of cases according to age frequency. 12 cases (27.3\%) were of 20 or below 20 years, 9 cases $(20.4 \%)$ were of 21 to 30 years age group, while 31 to 40 years age group comprises of 11 cases (25\%).

Table-II

Distribution of the cases by presenting symptoms $\left(N=44^{*}\right)$

\begin{tabular}{lcc}
\hline $\begin{array}{l}\text { Presenting } \\
\text { symptoms }\end{array}$ & No. of cases & Percentage \\
\hline Headache & 36 & $81.8 \%$ \\
Vomiting & 29 & $65.9 \%$ \\
H/O Convulsion & 26 & $59 \%$ \\
H/O altered consciousness & 19 \\
43.2\% & & \\
Blurring of visual & 21 & $47.7 \%$ \\
Limb weakness & 20 & $45.5 \%$ \\
\hline
\end{tabular}

* Total was not correspond to $100 \%$, because of multiple symptoms in same patient

Table II shows the presenting symptoms of the study patients. More than $80 \%$ patients presented with 
headache, $65.9 \%$ of cases admitted with vomiting, nearly $60 \%$ had history of convulsion at least once during the period of illness.

Table-III

Distribution of the patients by status of consciousness $(N=44)$ :

\begin{tabular}{lcc}
\hline GCS score & No. of cases & Percentage \\
\hline 15 & 38 & 86.3 \\
$13-14$ & 5 & 11.4 \\
$7-12$ & 01 & 2.3 \\
\hline Total cases & 44 & 100 \\
\hline
\end{tabular}

Table III shows the consciousness level of the patients. 38 patients $(86.3 \%)$ were found conscious oriented. 5 cases (11.4\%) were confused (GCS, 1314) and 1 patient had GCS 7-12.

Table-IV

Distribution of the cases by speech pattern and gait $(N=44)$ :

\begin{tabular}{lcc}
\hline Speech pattern & No. of cases & Percentage \\
\hline Normal & 35 & 79.6 \\
Dysphasia & 6 & 13.6 \\
Dysarthria & 3 & 6.8 \\
Gait pattern & & \\
Normal & 24 & 54.5 \\
Hemiplegic & 19 & 43.2 \\
Ataxic & 01 & 02.3 \\
\hline
\end{tabular}

Table IV shows the speech pattern of the patients. Put of 44 patients 35 cases $(79.6 \%)$ did not have any speech defect. Out of 44 patients 24 (54.5\%) had normal gait.

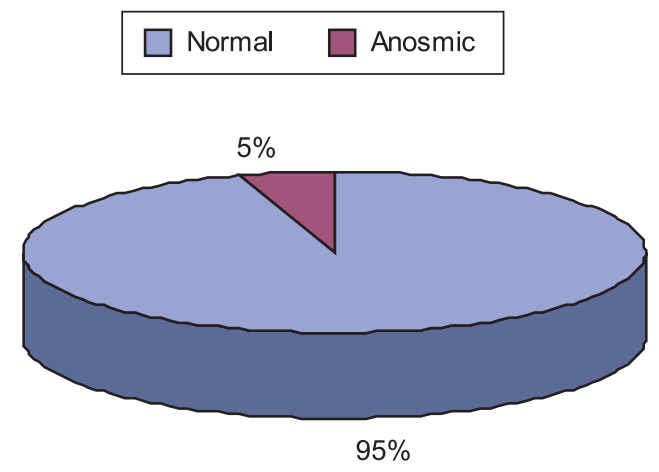

Fig.-2: Distribution of the cases by olfactory nerve function $(N=44)$ :
Fig.-2. shows most of the cases (95.5\%) had normal Olfactory nerve function while only 2 cases (4.5\%) had anosmia.

Table-V

Optic nerve function occulomotor, trochlear abducement nerve

\begin{tabular}{lcc}
\hline Optic nerve function & No. of cases & Percentage \\
\hline Normal & 16 & 36.4 \\
Defective acuity of vision & 08 & 18.2 \\
Defective field of vision & 05 & 11.4 \\
Papilloedema & 17 & 38.6 \\
Optic atrophy & 06 & 13.6 \\
Oculomotor, trochlear and & & \\
abducent nerves function & & \\
Normal & 40 & 90.9 \\
Abnormal size of pupil & 4 & 9.1 \\
Extraocular palsy & 01 & 2.3 \\
\hline
\end{tabular}

* Total was not correspond to $100 \%$, because of multiple symptoms in same patient

Table $\mathrm{V}$ shows the distribution of patients by the status of optic nerve, $36.4 \%$ of the patients had normal optic nerve function while $38.6 \%$ had papilloedema and $13.6 \%$ had optic atrophy. The functional status of Oculomotor, trochlear and abducent nerves. $90.9 \%$ of the patients had normal function, 4 cases (9.1\%) had abnormal size of pupil and 1 patient (2.3\%) had extraocular muscle palsy. Regarding the function of Trigeminal, Glossopharyngeal, Vagus, Accessory and Hypoglossal nerves all the patients were found to be normal.

Table-VI

Function of facial nerves (N-44)

\begin{tabular}{lcc}
\hline Nerves function & $\begin{array}{r}\text { No. of } \\
\text { cases }\end{array}$ & Percentage \\
\hline Facial nerves function & 34 & 77.3 \\
Normal & 10 & 22.7 \\
Upper motor type deficit & 0 & 0 \\
Lower motor type deficit & 0 & \\
Vestibulocochlear nerves function & 95.5 \\
Normal & 42 & 4.5 \\
Hearing impairment & 2 & 0 \\
Balance impairment & 0 &
\end{tabular}


Table VI shows the function of facial nerves. $77.3 \%$ of the patients were found to have normal function of facial nerves whereas $22.7 \%$ of them had upper motor type of facial palsy. The function of vestibulocochlear nerves. $95.5 \%$ of the patients were found to have normal function and the rest (4.5\%) of them had hearing deficit.

\section{Table-VII}

Motor Function, sensory function and cerebellar function (N-44)

\begin{tabular}{lcc}
\hline Function & No. of cases & Percentage \\
\hline Motor function & & \\
Normal & 27 & 61.4 \\
Hemiparetic & 16 & 36.4 \\
Monoparetic & 1 & 2.2 \\
Sensory function & 44 & 100 \\
Normal & 43 & 97.7 \\
Impaired pain and temperature & 0 & 0 \\
Impaired cortical sensation & 1 & 2.3 \\
Cerebellar function & & \\
Normal & 43 & 97.7 \\
Impaired & 1 & 2.3 \\
\hline
\end{tabular}

Table VII shows the motor function of the patients. $61.4 \%$ of the patients did not have any motor deficit, 16 cases (36.4\%) had hemiparesis and I patient presented with monoparesis. The sensory function of the patients. $97.7 \%$ of the patients did not have any sensory deficit and only 1 patient (2.3\%) showed impairment of cortical sensation. The cerebellar function of the patients. $97.7 \%$ of the patients had normal coordination of movements and only 1 patient (2.3\%) showed impairment of cerebellar function.

Table-VIII

Distribution of the cases according to CT / MRI findings ( $\mathrm{N}-44)$

\begin{tabular}{lcc}
\hline CT / MRI Findings & No. of cases Percentage \\
\hline $\begin{array}{l}\text { Change in attenuation, } \\
\text { no mass effect,no }\end{array}$ & 1 & 2.3 \\
enhancement & & \\
$\begin{array}{l}\text { Change in attenuation + } \\
\text { mass effect ,no } \\
\text { enhancement }\end{array}$ & 19 & 43.2 \\
$\begin{array}{l}\text { Enhancement but } \\
\text { no necrosis }\end{array}$ & 16 & 36.3 \\
$\begin{array}{l}\text { Enhancement with necrosis } \\
\text { (ring enhancement) }\end{array}$ & 8 & 18.2 \\
\hline Total cases & 44 & 100 \\
\hline
\end{tabular}

Table VIII Imaging study of 19 patients (43.2\%) showed change in attenuation, mass effect without any enhancement of contrast agent. Imaging of $36.3 \%$ patients showed contrast enhancement without necrosis $18.2 \%$ of them showed enhancement with necrosis and imaging of one patient (2.3\%) showed only attenuation change without mass effect and enhancement.

Table-IX

Distribution of the patients according to histopathological subtypes (N-44)

\begin{tabular}{lcc}
\hline $\begin{array}{l}\text { Histopathological } \\
\text { subtypes }\end{array}$ & No. of cases & Percentage \\
\hline WHO Grade I & 15 & 34.1 \\
WHO Grade II & 10 & 22.7 \\
WHO Grade III & 9 & 20.5 \\
WHO Grade IV & 10 & 22.7 \\
\hline Total cases & 44 & 100 \\
\hline
\end{tabular}

Table IX presents the distribution of the patients according to histopathological subtypes. WHO grade I astrocytomas were found in 15 cases (34.1\%). WHO grade II were found in 10 cases (22.7\%), 9 cases (20.5\%) were in WHO grade III and rest of the cases were in WHO grade IV astrocytoma. They were 10 cases (22.7\%).

Table-X

Mean age of the different histopathological subtypes (N-44)

\begin{tabular}{lccc}
\hline $\begin{array}{l}\text { Histopathological } \\
\text { subtypes }\end{array}$ & $\begin{array}{c}\text { Mean age } \\
\text { (years) }\end{array}$ & $\begin{array}{c}\text { Standard } \\
\text { deviation }\end{array}$ & $\begin{array}{c}\text { Mean age } \\
\text { of all cases }\end{array}$ \\
\hline WHO Grade I & 23.7 & 13.30 & \\
WHO Grade II & 30.7 & 5.30 & 33.1 \\
WHO Grade III & 36.4 & 19.90 & \\
WHO Grade IV & 46.5 & 12.02 & \\
\hline
\end{tabular}

From table $X$ we get the information that mean age of WHO grade I (pilocytic astrocytoma and subependymal giant cell astrocytoma) patients was 23.7 years, mean age of WHO grade II (low grade astrocytoma) was 30.7 years, mean age of WHO grade III ( anaplastic astrocytoma) was 36.4 years and mean age of WHO grade IV (glioblastoma multiforme) was 46.5 years. When we calculated 
Relationship between age groups and histopathological subtypes:

Table-XI

Cross tabulation of age group and histopathological subtypes (N-44)

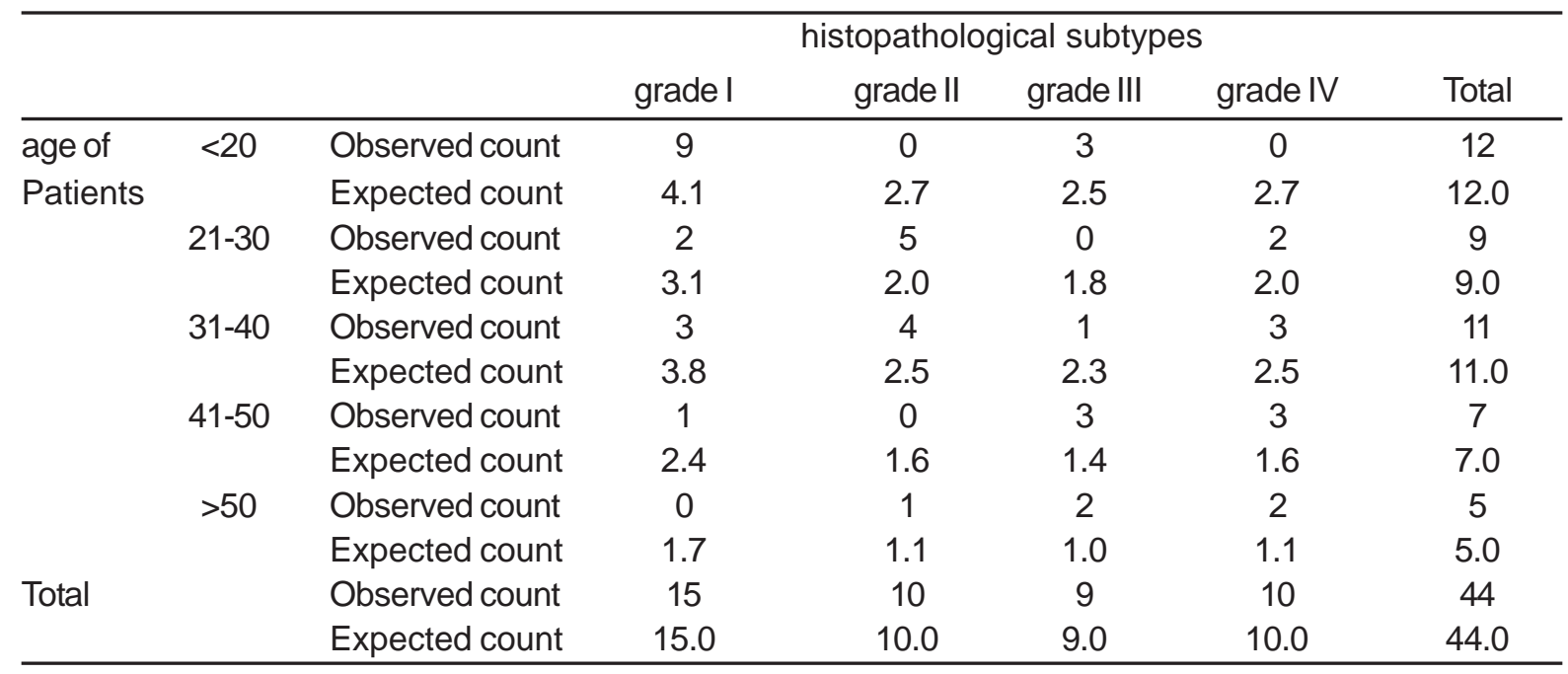

the mean age of all the 44 patients it was 33.1 years (SD \pm 15.6 ).

Above table IX shows in 20 or less than 20 years age group highest number of cases found in Grade I subtype. In both 21-30 and 31-40 years age group highest frequency was observed in Grade II subtype, in 41-50 years age group highest frequency was in both Grade III and Grade IV and in more than 50 years age group highest number of observation was in Grade III and IV too.

After preparing the above 20 cells table Chi-square $\left(\chi^{2}\right)$ test was applied and value of $\chi^{2}$ comes to 28.46 where degree of freedom $=(4-1) \times(5-1)$ or 12 . at 12 degrees of freedom table value of is 21.13 when $p<.05$ and 26.12 when $p<.01$.

Here the calculated value of $\chi^{2}$ is higher than the table value at $1 \%$ level of significance $(p<.01)$. Hence the test is significant.

So there is association between age group and histopathological subtype in case of intracranial astrocytoma patients.

Discussion

Age incidence of intracranial astrocytomas is a very important variable which varies from study to study. Age incidence of astrocytoma was 31.51 years in Dastur's (1969) series ${ }^{22}$.
According to the study of McKeran and Thomas mean age for low grade astrocytomas was 37.4 years, for anaplastic astrocytomas 45.8 years and for glioblastoma multiforme 52 year ${ }^{23}$.

According to Youman's study, pilocytic astrocytomas occurred in childhood, low grade astrocytomas are non contrast enhancing area usually present in fourth decades ${ }^{4}$.

According to Osborn ${ }^{2}$ pilocytic astrocytomas typically are tumors of children and young adult.

In our study we found that mean age of low grade astrocytomas (WHO grade I) was 30.7 years. This is almost similar to other international studies. Mean age of anaplastic astrocytoma (grade III) was 36.4 years, which is little earlier than the other studies. In case of glioblastoma multiforme mean age was 46.5 years, which is near to the study of McKeran and Thomas ${ }^{24}$. Mean age of pilocytic astrocytomas (grade I) was 23.7 years, which is little older than the international studies where it was during the first two decades of life.

In our study mean age of all intracranial astrocytoma patients was 33.1 yaers which is very close to the result of Dastur's (31.51 years) study.

Sex incidents of intracranial astrocytomas also varies from study to study. In our study, we found a 
male predominance at the ration of 4.5:1. So, if we compare our study with other international studies, we will find more male predominance.

In this study highest number of cases were found in less than 20 years group and it was 15 cases. The youngest patient was 1 year old and the oldest patient was 65 years old showing that no age group is exempted for intracranial astrocytomas.

In our study the percentage of glioblastoma multiforme was $22.7 \%$ which is surprisingly low than the international studies where it was the common of all gliomas. Probably poor prognosis and rapid deterioration may be one of the important cause of not reaching of such types of patients in hospital in proper time. Headache or seizure is sometimes the early or only symptom for intracranial astrocytoma patients which are ignored by a lot of patients or attendant vary frequently. Investigation of intracranial astrocytoma patients (CT/MRI) are very expensive which were also avoided by the patients or their relatives very frequently which is another important cause of not reaching hospital in time.

Analysis of clinical features revealed that presenting symptoms were headache, vomiting, convulsion, altered consciousness, blurring of vision, limb weakness and cranial nerve dysfunction. Most of the symptoms were related to raised intracranial pressure and mass effect by the tumor.

Jackle et al. reported seizure in $65-70 \%$ of low grade glioma and $30-50 \%$ in glioblastoma patients ${ }^{24}$.

Tandon showed apathy, change in personality, impaired memory attention concentration and inappropriate social behavior are the common feature of fronto temporal astrocytomas ${ }^{25}$.

In this study we observed $81.8 \%$ patients presented with headache, $59 \%$ of the patients had history of seizure, $47.7 \%$ of them had visual disturbance and limb weakness was present in $45.5 \%$ of the patients. So, the presenting symptoms of this study is almost similar to other studies.

McKeran and Thomas reported $50-70 \%$ patients with papilloedema. ${ }^{16}$ In our study $38.6 \%$ of the patients had papilloedema which is very near to that study.
This study showed $77.3 \%$ of the patients with normal facial nerve function and $22.7 \%$ with upper motor type deficit.

In this study $79.6 \%$ patients were found with normal speech, $13.6 \%$ with dysphasia and $6.8 \%$ with dysarthria. Early dysphasia is often overlooked or confused with memory impairment ${ }^{25}$.

In imaging (CT / MRI) study $36.4 \%$ patients had complex enhancement, $18.2 \%$ had enhancement with necrosis and rest $45.4 \%$ without enhancement. Piepmier ${ }^{26}$ had shown in a large series that those patients whose tumors enhance on imaging had a poorer prognosis than those whose lesion did not enhance after administration of $\mathrm{I} / \mathrm{V}$ contrast.

In this study, mean age of WHO grade I is 23.7 years, WHO grade II is 30.7 years, WHO grade III is 36.4 years and WHO grade IV is 46.5 years. So the histopathological subtypes of astrocytomas are related to age group.

\section{Conclusion:}

This study has shown that there is significant relationship between age groups and histopathological subtypes in case of intracranial astrocytoma patients.

\section{Reference:}

1. Angevine JB Jr. The Neuroglia, BNI Quart 1988;4: 21-34.

2. Osborn AG. Diagnostic Neuroradiology, Mosby-Year Book. Inc., USA, 1994; 529-60.

3. Okazaki H. Neoplasm and related lesions, in Fundamentals of neuropathology, $2^{\text {nd }} \mathrm{ed}$. New York, Igaku-Shoin. 1989; 2: 203-74.

4. Youmans JR. Neurological Surgery, $4^{\text {th }}$ ed, W B Saunders, USA. 1997; 2810, 2829.

5. Rengachari SS. Principles of Neurosurgery, Mosby-wolfe, USA. 1994;26.3.

7. Daumas-Duport C, Scheithauer B, O'Fallon J. Grading of Astrocytomas: a simple and reproducible method.Cancer 1998; 62: 2152-65.

6. Kernohan J.W, Sayre GP Atlas of Tumor Pathology, Section X, Fascicles 35, 37: Tumors of the Central Nerveous System. 
Washington DC: Armed forces institute of pathology, 1952;22-42.

8. Burger PC, Vogel FS. Surgical Pathology of the Nervous System and Its coverings. $2^{\text {nd }} \mathrm{ed}$. New York, NY:John Wiley and Sons; 1982; 226-266.

9. Zulch KJ. Histological typing of Tumors of the Central Nervous System, International Histological Classification of Tumors, No 21, World Health Organisation, Geneva 1979.

10. Burger PC, Scheithauer BW, Vogel FS. 1991. Surgical Pathology of Nervous System and its coverings, $3^{\text {rd }}$ ed, New York: Churchill Livingstone 1979; 193-405,

11. Zulch KJ. Brain Tumors, Their biology and Pathology, Springer-Verlag, Berlin 1986; 221-32.

12. Palma L, Guidetti B. Cystic pilocytic astrocytomas of the cerebral hemispheres, $\mathrm{J}$ Neurosurg 1985;62:811-25.

13. Lu Y-Y, Van Tassel P, Brunner JM et al. Juvenile pilocytic astrocytomas; CT and MR characteristics, AJNR 1989;10: 363-70.

14. Smirniotopoulas JG, Parisi J, Murphy F: Cerebral hemispheric astrocytoma: radiologicpathologic correlation. Presented at the $87^{\text {th }}$ annual meeting of the American Roentgen-Ray Society, Miami, Florida, 1987.

15. Dastur DK, Lalitha VS. Pathological analysis of intracranial space occupying lesion in 1000 cases including children. Part 2. Incidence, type and unusual cases of gliomas. J Neurol Sc 1969; 143.

16. Mckeran RO, Thomas DGT. The clinical study of gliomas. In: Thomas DGT and Graham DI, eds. Brain Tumors: Specific basis, clinical investigation and current therapy. London: Butterworth 1980; 194-230.
17. Burger PC, Vogel S,Green SB. Glioblastoma multiforme and Anaplastic Astrocytoma : Pathologic criteria and prognostic implications. Cancer 1985; 56: 1106-1111.

18. Jellinger K. Pathology of human intracranial neoplasm. In : Therapy of malignant Brain Tumors, ed. Jellinger K. Springer-Verlag, Berlin 1987; 23-7.

19. Mahaley MS, Mettlin C, Natarajan N. National Survey of patterns of care for brain tumor patients, J Neurosurg 1989;71 : 826-836.

20. MacDonald T. Astrocytoma, Am J Neurol 2002; 2: 325-30.

21. Frankel SA and German WT. Glioblastoma multiforme : review of 219 cases with regard to natural history,pathology, diagnostic methods and treatment, J Neurosurg 1954;15: 489-503.

22. Dastur DK, Lalitha VS. Pathological analysis of intracranial space occupying lesion in 1000 cases including children. Part 2. Incidence, type and unusual cases of gliomas. J Neurol Sc 1969;143.

23. Mckeran RO, Thomas DGT. The clinical study of gliomas. In: Thomas DGT and Graham DI, eds. Brain Tumors : Specific basis, clinical investigation and current therapy. London :Butterworth 1980;194-230.

24. Jackle KA, Cohen ME and Dufner PK. Clinical presentation and therapy of nervous system tumors, In : Bradley WG, Baroff RB, Fenichel GM.(eds.), Neurology In clinical practice, $2^{\text {nd }}$ ed. Butterworth-heniman,Boston 1996; 1131-49.

25. Tandon PN. Supratentorial glioma: The unrelenting challenge, J Neurol 1994;42:131.

26. Piepmier GM. Observation on the current treatment of low grade astrocytic tumors of the cerebral hemisphere. J Neurosurg 1987; 67: 177-81. 